\title{
Detección de estructuras temporales en baloncesto
}

\section{Detection of temporal structures in basketball}

Pic Aguilar, M.

Dpto. de Didácticas Especificas, Universidad de La Laguna

\begin{abstract}
Resumen: Resumir un partido de baloncesto a la efectividad en el lanzamiento, rebotes ofensivos y/o defensivos, entre otros indicadores; puede ser arriesgado, partiendo de la complejidad relacional existente en un partido de baloncesto. A pesar de ello, tradicionalmente ha sido investigado el éxito en baloncesto sobre datos sin una referencia temporal. La identificación de regularidades temporales y conductuales puede ser un reto de investigación que ayude a concretar la planificación de entrenamientos, así como la optimización estratégica de los equipos. El registro temporal de aciertos y fallos en el lanzamiento entre otros indicadores, puede ofrecer una dependencia temporal ineludible, invisible a una mirada aparente. Es este el propósito primordial del trabajo para optimizar las estrategias puestas en práctica en los partidos y con ello, la concreción de rutinas más ecológicas de acuerdo con las demandas de los partidos en los entrenamientos. Fue empleada una metodología observacional con un diseńo nomotético, puntual y multidimensional para el registro de conductas motrices organizadas en torno a un sistema mixto de registro 'had oc'. Para el análisis de la dimensión temporal de los registros fue empleada la técnica T-patterns (Magnusson, 2000), posibilitando así, la identificación de asimetrías motrices. Los resultados muestran regularidades temporales y estratégicas más relevantes. La identificación de itinerarios estratégicos de los equipos revelan la acomodación funcional entre los equipos. Palabras Clave: baloncesto, metodología observacional, t-patterns, interacción motriz
\end{abstract}

Abstract: Summarizing a basketball game to effectiveness at launch, offensive rebounds and / or defensive, among other indicators; it can be risky, based on the relational complexity existing in a basketball game. However, traditionally; it has been investigated success in basketball on data without a time reference. Temporary identification and behavioral regularities can be challenging research to help realize training planning and strategic optimization of equipment. The temporary record of successes and failures in launching among other indicators, can provide an unavoidable time dependence, invisible to an apparent look. This is the primary purpose of work to optimize strategies implemented in matches and thus the realization of greener routines according to the demands of the parties in training. It was an observational methodology used a nomothetic, punctual and multidimensional design for the registration of motor behavior organized around a mixed system of registration 'had oc'. For the analysis of the temporal dimension of the records it was used the technique T-patterns (Magnusson, 2000), thus enabling the identification of motor asymmetries. The results show most relevant temporal and strategic regularities. The identification of strategic pathways teams reveal functional accommodation between the teams.

Key Words: basketball, observational methodology, t-patterns, motor interaction

\section{Introduction}

Getting to know why some basketball teams are more successful than others is a complex line of research. Knowing what actions or group of actions are more critical to make a difference in high competition does not always respond to a causal relationship. In this sense, observational methodology offers an ecological alternative to identify motor situations, by analyzing behavioral chains. Regarding the achievement of goals in football or basketball baskets, collaborative interaction with peers and antagonistic with rivals seems to be a key concept. Motor interaction (Parlebas, 2001) is essentially relational, and affects the decision making of the players, since they have to discriminate and select effective motor responses for teams. In basketball, actions of collaboration and rivalry occur at a high speed, and this could be another indicator of decisional complexity. Thus, all motor responses are subject to the binomial compound of speed and motor adjustment (Mahlo, 1969), so that decision making is the

Dirección para correspondencia [Correspodence address]: M. Pic Aguilar, Dpto. de Didácticas Específicas, Universidad de La Laguna (Espańa) E-mail: pic.aguilar.90@ull.edu.es cornerstone for analyzing game action in basketball. Therefore, solving problem situations or deciding what to do and how to do it from a relational approach, refers directly to the decision-making structure of the role (Pic, \& Navarro In press) and its motor behavior as a resulting response.

Due to the relational structure of basketball, peers try to braid actions in what we might call motor synergy (Araújo, Silva, \& Ramos, 2014). Failing to pay attention to this relational capacity with peers, would reduce the analysis of success in basketball (Courel, Suárez, Ortega, Piñar, \& Cárdenas, 2013; Erčulj \& Štrumbelj, 2015) to random factors in a particular motor situation. Although throw effectiveness (Fernández, Camerino, Anguera, \& Jonsson, 2009; Yaari \& Eisenmann, 2011) is an essential indicator to explain the outcome of a basketball game, even though this would not explain by itself how teams play, it does downplay the importance of having more ball possessions, since teams with few but effective possessions could prove themselves superior to opponents who do not have high percentages of effectiveness (Ibáñez, Feu, \& Dorado, 2003).

Coaches often select play models consistent with the 
characteristics of their players. In this sense, in basketball you can refer to attack and duration phases, the number of players taking part in the attacks, the number of passes, the number of collective strategies used in the attacks, efficacy and type of attack put in practice (Ortega, Cárdenas, Sainz de Baranda, \& Palao, 2006). In line with the collective strategy, low percentages of success in shots with concrete actions could be identified (Fernández., et al, 2009), and also the influence of the pass in basketball (Courel., et al, \& 2013). To calculate the index of intensity of the attacks, the duration of the attacks and the technical and tactical elements (bounces, passes, shots, direct and indirect picks) (Bazanov, Vōhandu, \& Haljand, 2006) was suggested, while seven indicators were used to define the style of play (phases and duration of attacks, number of players in the attacks, number of passes, collective strategies used in the attacks, type and effectiveness of the attack (Ortega., et al, 2006).

The use of an observational methodology (Anguera, Magnusson, \& Jonsson, 2007; Lapresa, Álvarez, Arana, Garzón, \& Caballero, 2013; Lapresa, Camerino, Cabedo, Anguera, Jonsson, \& Arana, 2015; Zurloni, Cavalera, Diana, Elia, \& Jonsson, 2014) offers the possibility of registering observable behaviors to help to identify basketball game sequences. The shot (Fernández., et al, 2009) or playing action (Garzón, Lapresa, Anguera, \& Arana, 2011) was analyzed according to this methodology, to try to reveal regularities which took place during the games, but were hidden from an apparent look. Some analysis traditionally used by the well-established observational methodology (Anguera \& Hernández-Mendo, 2014; Anguera \& Hernández-Mendo, 2016) applied analysis which did not include the time dimension. While recognizing that this type of analysis can be interesting to achieve other goals that are not those of this work, it is imperative to analyze basketball game action in its more ecological status, which is from its temporal dimension. Including temporality in the registration of motor events refers directly to the use of the Theme analysis technique (Magnusson, 1996; 2000). This technique is particularly suitable when trying to make a relational analysis of the complexity (Morin, 1990) which exists in basketball games.

With the previously mentioned background, the objective of the study was to identify basketball game action and, by doing it, to try to reveal similarities and differences between the teams analyzed. The use of this study goes through checking what importance can offer each of the categories to form game action in teams playing at a high level. Determining which categories are included in temporal patterns involving an approach to victory or defeat will be crucial. The strategic optimization of the teams can offer an unavoidable time dependence to optimize the strategies implemented in games, thus attaining more ecological routines according to the demands in a real situation.

\section{Method}

One of the properties of observational methodology is its ability to adapt to different environments, that is, its flexibility without resenting in terms of scientific rigor. Using the temporal algorithm designed by Magnusson (2000), the temporal structure of motor behavior chains is identified, and the observational methodology is its faithful ally in order to make targets viable. The observational methodology addresses not only the final record, but also the treatment of the data or how these data should be collected, among other considerations.

\section{Observational Design}

An observational methodology was selected, by using a quadrant III insert design in (Anguera, Blanco-Villaseñor, Hernandez-Mendo, \& Losada, 2011). Within this quadrant, it is a nomothetic study, because actions were recorded by monitoring the responses made by different players located around the ball; punctual; since no track of the different record units was done, and just one match was considered; while it is a multidimensional design, because different categories grouped by criteria were registered.

\section{Participants}

For the study, the 2012 London Olympic Games basketball final was selected, disputed between absolute men's national teams of Spain and the United States. It is a purposive sampling (Anguera, Arnau, Ato, Martínez, Pascual, \& Vallejo, 1995; Nunes, Iglesias, Daza, Irurtia, Caparrós, \& Anguera, 2016), since it is not intended represent the population to generalize results. Since the found images were taken from the official website of the International Olympic Committee (IOC) and from YouTube, the protocol monitoring described in the American Psychological Association (American Psychological Association, 2002) was not performed.

\section{Instrument}

In order to o address the presumption of completeness, the registration system took into account the image analysis of previous basketball games by observers, to ensure no new categories emerged. The categories are mutually exclusive, so that the presence of one of them disabled the possibility of a different one registering on the same criterion. Table 1 collected 22 categories grouped under three criteria, used by the observers for registration. Within the first criterion (Team) we find the names of the two teams, while in the second one (Offensive) the sixteen categories were separated to develop offensive actions such as actions which indicated passes or 
shots. Finally, through the third criterion (Defensive), defensive actions were recorded.

Table 1. Mixed recording system used by the evaluators, based on 3 criteria and 22 categories.

\begin{tabular}{|c|c|}
\hline Criterion & Codes and categorical description \\
\hline Teams & $\begin{array}{l}\text { S: Spain's possession of the ball. } \\
\text { E: USA's possession of the ball. }\end{array}$ \\
\hline Offensive & $\begin{array}{l}\text { ep: Entry pass; } \\
\text { ip: inbounds pass. } \\
\text { p: pass. } \\
\text { d: drive. } \\
\text { tpe: effective three-point shots. } \\
\text { tpi: ineffective three-point shots. } \\
\text { tpse: effective two-point shots. } \\
\text { tpsi: ineffective two-point shots. } \\
\text { ose: effective free-throws. } \\
\text { osi: ineffective free-throws. } \\
\text { lde: effective lay-outs, dunks or scored baskets } \\
\text { without air phase. } \\
\text { ldi: ineffective lay-outs, dunks or scored baskets } \\
\text { without air phase. } \\
\text { lb: balls lost by the team in possession of the ball. } \\
\text { or: Offensive rebounds. } \\
\text { md: The ball crosses the midline. } \\
\text { fo: Foul on a player in possession of the ball. }\end{array}$ \\
\hline Defensive & $\begin{array}{l}\text { Sb: Stealing the ball with participation of the rival's } \\
\text { defense. } \\
\text { fd: foul. } \\
\text { dr: defensive rebound. } \\
\text { bs: block. }\end{array}$ \\
\hline
\end{tabular}

\section{Procedure and Data Quality}

The encoded registration (Figure 1) was performed by using LINCE software v.1.1 (Gabín, Camerino, Anguera, \& Castañer, 2012), on images downloaded from the website YouTube. The records were subjected to data quality control. For the quality of records, concordance between records made by two independent observers in two different moments, with a separation of two weeks, double-blind conducted by two perspectives:

a) From a classical perspective, in which Pearson and Kendall's Tau b correlations were taken into account. Within intra evaluator reliability, the first observer got a 0.890 (Kendall's Tau b) and 0.974 (Pearson) reliability when registering at two different times, while the second observer repeated the experience getting 0.877 and 0.984 respectively. The inter observer values were performed in the same way, always reaching values accepted in social sciences, above 0.85, with Kendall and Pearson.

b) From the perspective of Generalizability Theory (Cronbach, Gleser, Nanda, \& Rajaratnam, 1972), through which indices of reliability and generalizability were obtained. Interobserver and intraobserver reliability were calculated through a facets design (observer and categories) and (time and categories). Variance components were estimated in a nonending way, revealing the unmistakable source of variability. These facets presented absolute and relative generalization coefficients close to one, so that the quality of the records would be ensured. Thus, records quality was assured.

Figure 1. Recording instrument: LINCE (Gabin, Camerino, Anguera, \& Castañer, 2012).

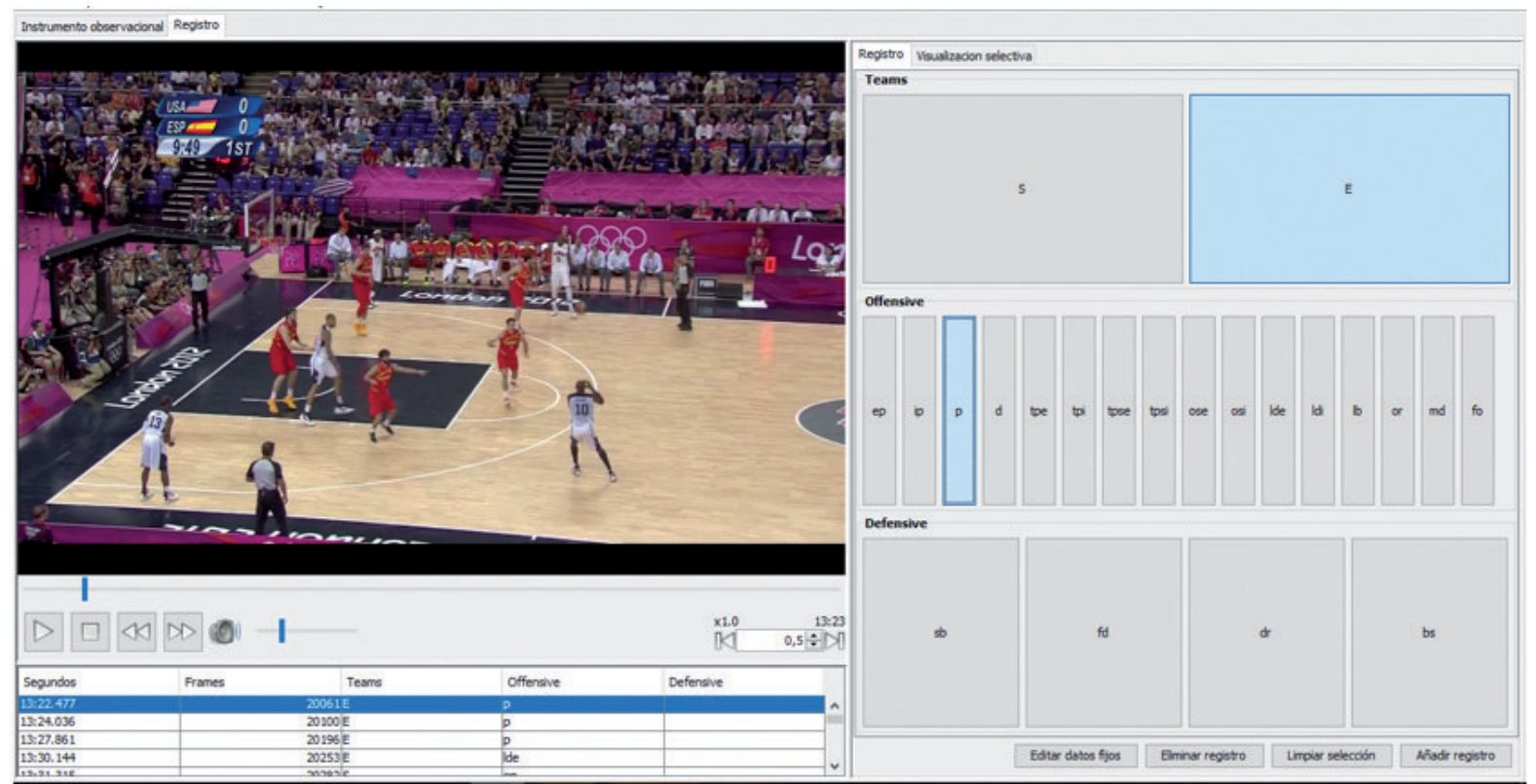




\section{Results}

The plot of time event (figure 2) was generated by Theme (Magnusson, 2000) and showed the existence of behavioral regularity. Blue dots indicate temporal behaviors that were part of a pattern while driving the red dots indicate the opposite, ie, behaviors that were left out of any pattern or regularity.

Figure 2. Temporal distribution of behaviors of the registration system in the basketball game that pitted national teams of Spain and the US, London 2012 Olympic Games.

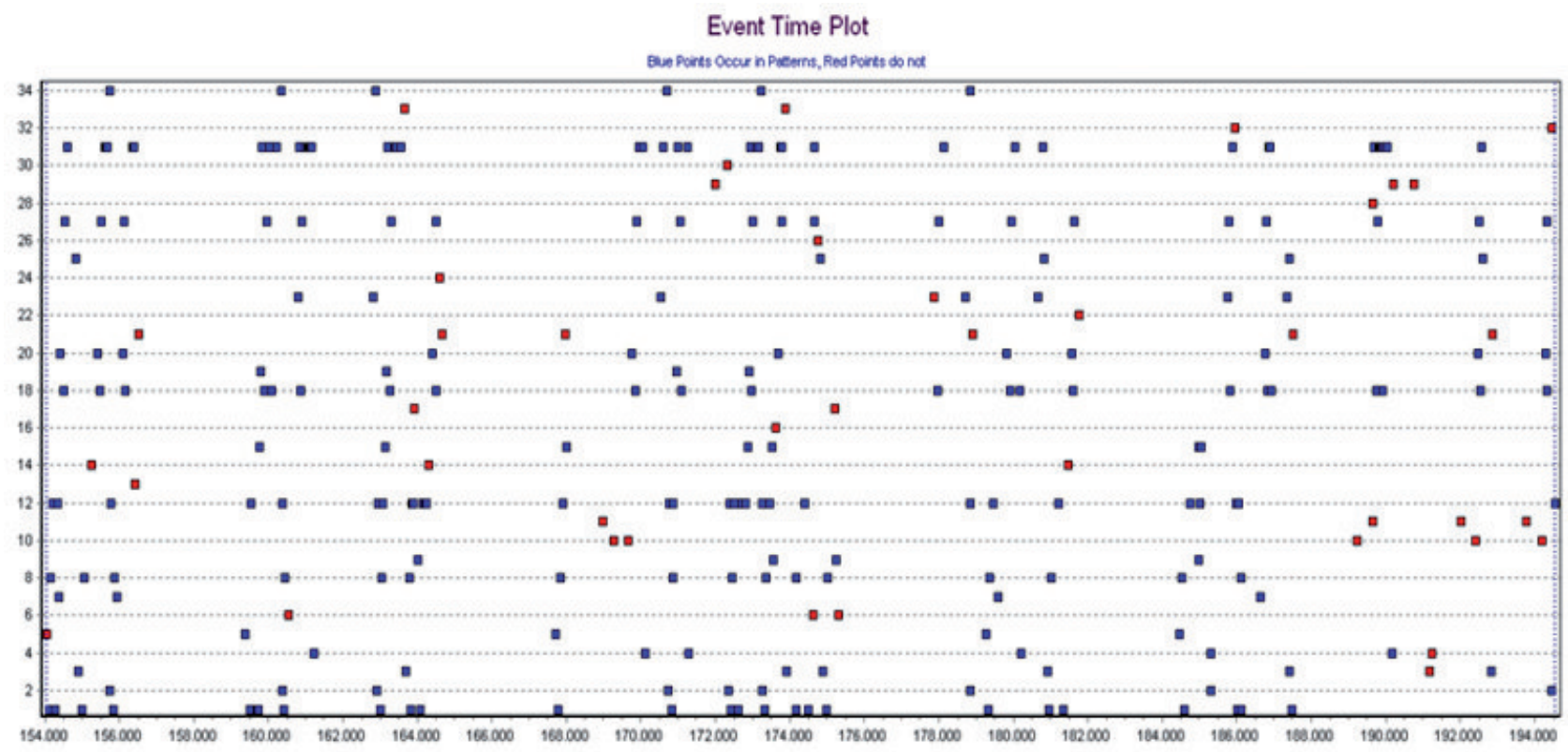

Figure 3. Theme allows to detect complex repeated temporal patterns even when a multitude of unrelated events occur. The order of the occurrences and the time distance between events are essential requirements to be detected as a T-patterns. In the example, $((\mathrm{ab})(\mathrm{cd}))$ or $((\mathrm{a}(\mathrm{bc})) \mathrm{d}))$ among others.
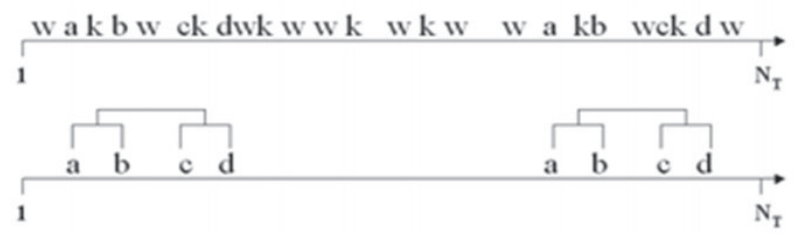

According to Magnuson (2000, p-94-95) 'if A is an earlier and $\mathrm{B}$ a later component of the same recurring T-pattern, then, after an occurrence of $A$ at $t$, there is an interval $[t+d 1$, $\mathrm{t}+\mathrm{d} 2](\mathrm{d} 2 \geq \mathrm{d} 1 \geq \mathrm{d} 0)$ that tends to contain at least one occurrence of $\mathrm{B}$ more often than would be expected by chance'.
It may be noted (Table 2) that the selection of the US was more diversified than the Spain game action. While the US were able to identify 15 final will conduct regular temporal patterns of action game, Spain was assigned to conduct less, triggering motive pattern.

During the first quarter, the US team turned to make mistakes on the opposing team (fd) like Spain, however, the temporal pattern of Spain found that players driving the ball (d). This is a difference between the two teams. first quarter was evident in the same as the Spanish team performed passes between players before appropriating offensive rebounds (or), whereas in the US it was found that both the preparation of actions effective launch of three points (tpe) and ineffective two points (tpsi) were attempts to make baskets previous passes (p), especially with the launch of two points. 
Table 2. Temporal patterns identified by taking each registration system behavior categories as final behaviour. Parentheses indicate recurrence (temporary and sequential) identified by the software theme.

\begin{tabular}{|c|c|c|c|}
\hline Quarter & Category & EEUU & SPAIN \\
\hline \multirow[t]{6}{*}{$1^{\circ}$} & ep & & (e,md s,ep) \\
\hline & $\mathrm{fd}$ & $(((e, m d$ e,p $) s, m d)$ e,fd $)$ & $((((s, p(s, d$ s,p $))($ e,ep e,md $))($ e,p e,p $))($ e,p s,fd $))$ \\
\hline & $\mathrm{md}$ & & $((\mathrm{e}, \mathrm{md} \mathrm{e}, \mathrm{p}) \mathrm{s}, \mathrm{md})$ \\
\hline & or & & $((s, p s, p) s, o r)$ \\
\hline & tpe & ( e,p e,tpe) & \\
\hline & tpsi & $((\mathrm{e}, \mathrm{p}$ e,p $)$ e,tpsi $)$ & \\
\hline \multirow[t]{8}{*}{$2^{\circ}$} & ip & $((e, d s, f d)$ e,ip $)$ & \\
\hline & $\mathrm{dr}$ & $(\mathrm{s}, \mathrm{d}(\mathrm{s}, \mathrm{md}(\mathrm{s}, \mathrm{p}$ e,dr $)))$ & $((e, d$ e,p $)($ e,tpi s,dr $))$ \\
\hline & $\mathrm{fd}$ & $((s, p(s, d s, p)) e, f d)$ & \\
\hline & tpi & $(\mathrm{e}, \mathrm{d}(\mathrm{e}, \mathrm{p}$ e,tpi $))$ & \\
\hline & or & (e,tpi e,or) & \\
\hline & tpsi & & $(((($ e,ep e,d $)($ e,md e,p $))(s, d(s, m d ~ s, p))) s, t p s i)$ \\
\hline & lde & & $((((\mathrm{e}, \mathrm{md}(\mathrm{s}, \mathrm{md} \mathrm{s}, \mathrm{p})) \mathrm{e}, \mathrm{ep})((\mathrm{e}, \mathrm{md} \mathrm{e}, \mathrm{d})(\mathrm{s}, \mathrm{d} \mathrm{s}, \mathrm{p})))(\mathrm{s}, \mathrm{d}$ s,lde $))$ \\
\hline & tpe & & $((s, \mathrm{md} s, \mathrm{p}) \mathrm{s}, \mathrm{tpe})$ \\
\hline \multirow[t]{7}{*}{$3^{\circ}$} & $\mathrm{dr}$ & & $(\mathrm{e}, \mathrm{d} s, \mathrm{dr})$ \\
\hline & ep & & $(($ e,md e,p ) s,ep ) \\
\hline & $\mathrm{fd}$ & $\begin{array}{l}(((\text { e,d e,md })((\text { e,p }((\text { s,ep s,d })(\text { s,md s,p }))) \\
(((\text { e,md e,p }) \text { s,md })(\text { s,p s,p })))) \text { e,fd })\end{array}$ & \\
\hline & $\mathrm{md}$ & & $((\mathrm{e}, \mathrm{md} \mathrm{e}, \mathrm{p}) \mathrm{s}, \mathrm{md})$ \\
\hline & ose & & $\begin{array}{l}(\mathrm{e}, \mathrm{md}((\mathrm{e}, \mathrm{p}((\mathrm{s}, \mathrm{md} \mathrm{s}, \mathrm{p})((\mathrm{e}, \mathrm{md} \mathrm{e}, \mathrm{p}) \mathrm{s}, \mathrm{md})))((\mathrm{s}, \mathrm{p} \text { s,p })(\mathrm{e}, \mathrm{fd} \\
\text { s,ose }))))\end{array}$ \\
\hline & tpi & $((e, p \quad e, p) e, t p i)$ & \\
\hline & lde & & $((s, p$ s,p $)$ s,lde $)$ \\
\hline \multirow[t]{6}{*}{$4^{\circ}$} & ip & $\begin{array}{l}(((\text { e,d ( e,md e,p ))( s,d ( s,md s,p ))) } \\
(((\text { e,ep ( e,d e,p ))( e,d s,md )) e,ip )) }\end{array}$ & \\
\hline & md & $(\mathrm{e}, \mathrm{d}$ e,md ) & \\
\hline & tpsi & $((\mathrm{s}, \mathrm{d}(\mathrm{s}, \mathrm{md} \mathrm{s}, \mathrm{p})) \mathrm{s}, \mathrm{tpsi})$ & \\
\hline & tpi & $(\mathrm{e}, \mathrm{d}(\mathrm{e}, \mathrm{p}$ e,tpi $))$ & \\
\hline & or & (e,md e,or) & \\
\hline & lde & & $(((($ e,p e,d $)$ s,ep $)($ s,md s,p )) s,lde $)$ \\
\hline
\end{tabular}

In the second quarter ((e, p) (e, tpi s, dr)) it was found that the selection of Spain caught offensive rebounds after lines (d) and passes (p) of the US, before trying to get hit three points but were ineffective (tpi). Before the Spanish team failed three-point shot could see US actions structured $((($ e, ep e, d) (e, md e, p)) (s, d (s, md s, p ))) s, tpsi). By selecting behavior (lde) as final behavior could be evidenced one of the most complex behavioral phrases party. That is, the Spanish team won basket from very close to the hoop places but previously driving occurrences (d) and passes (p) occurred. Effective launches two points were identified in the Spanish selection as final action before passing the ball through the midfield line (mp) and repeated passes between partners (p). In the US, it was found that three failed launches points (tpi) were preceded by passes ( $p$ ) and pipelines (d). Association between making personal fouls (fd) committed on the Spanish team, specifically on players leading the ball (d), crossing the ball the halfway line (md) or passing (p) the ball was found.

The defensive rebound was found in both teams $(\mathrm{dr})$ but while US corresponded with (s, d (s, md (s, e, dr))) whereas in Spain was ((e, p) (e, tpi s, dr)). That is, Spain caught defensive rebounds, prior ineffective release (tpi), line (d) and passes ( $p$ ) the opposing team, while in the US, defensive rebounds were final status of lines (d), crossing the ball the midline (md) and passaging (p). The selection of 
Spain found in the third quarter and behavioral temporal regularity $(e, d s, d r)$, ie capture defensive rebounds after driving the ball by opposing players. Another difference between the two teams would be the identification of a series of more structured temporary occurrences, specifically designed to make mistakes on Spain (fd) by the US team. Achieving launches a point by the Spanish selection was preceded by defensive fouls (fd) starring US and passes (p) of Spain, as it could be seen ((s, p s, p) (e, fd s, ose )))). While the US performed passes, missing the three-point ((e,p e, p) e, tpi), whereas the Spanish team performed passes to get deeper and get effective baskets over his rival hoop ((s, p s, p) s, lde).

In the fourth quarter, the Spanish team he was identified conducting close effective baskets to the hoop (((e, eg, d) s, ep) (s, md s, p)) s, lde), while USA offered a more diversified game action since he was found behavioral pattern to explain the final behavior (ip), (md), (tpsi), (tpi) and (or). Categories (tpsi) and (tpi) were preceded by pipeline (d) and passes (p), even before the launches failed three points failed also evidence crosses the line midfield (md) took into similar conditions are identified (tpi).

\section{Discussion and Conclusions}

This paper analyzed the action of game two basketball teams by using an observational methodology (Anguera., et al, 1995). Put the accent on identifying temporarily conducts regular analysis offers another perspective to help drive know what events are happening during match play high level, thus contributing to improve the design of training tasks.

Overall, the low coincidence in identifying patterns (Fernández., et al, 2009) behavior in action game both teams could reveal that each team is a decisional unit with autonomy, but always functional with respect to opponent. To get characterize the action of play equipment is necessary to reveal what kind of motor synergies (Araújo, Silva, \& Ramos, 2014) or collective aid system established between the players. However, the concept of motor interaction is more complex, also covering the rivalry (Parlebas, 2001) simultaneously in basketball.

Most categories have been identified as belonging to approach behavioral patterns 'attacker' which can be understood due to the imbalance between defensive and offensive actions of the registration system. It may surprise some categories (eg, tpse) have not appeared in the sequence of occurrences but must be taken into account that the timing of actual releases set to be random, always from the temporal approach on which rests the analysis tool Theme (Magnusson, 2000; 2005; 2006). You might think that performing countries could increase the effectiveness of releases (Yaari \& Eisenmann, 2011; Fernández., et al, 2009) however, it was not for any of the teams. Both teams were identified making passes with effective and ineffective releases, which could be interpreted as a search by the teams to get clear of rivals spaces, although releases not turn out always effective.

The ecological (Anguera \& Hernández-Mendo, 2014; Anguera \& Hernández-Mendo, 2016) value of using an observational methodology in basketball has been confirmed. The great effectiveness which was identified in three-point shooting (e, p e, tpe) by the United States, may partly explain the 35-27 score difference after the first quarter. However, the scoreboard in the second quarter showed a 24-31 difference in favor of Spain, and three-point shots by the Spanish team were identified by theme ((s, md s, p) s, tpe). During the third quarter, no effective shots were identified, but lde final actions ((s, p s, p) s, lde) were, and the result was 24-24. Finally, during the fourth quarter, the score was 24-18 in favor of the United States, with (lde) repeating as part of the t-patterns attributed to the Spanish team.

Certainly it remains a challenge, tackling the decisional complexity, action game in basketball. Among the limitations of this study, the composition of the sample is a limitation, and can be enriched by including more basketball games. Another limitation that could improve the study would include new criteria and categories that equilibrate the share register of attack and defense, as well as the focal player tracking, despite the problem of 'not observed' of some film sequences.

Identify temporal patterns in basketball competition can help improve understanding between the competition and training tasks. Each competition or each team can offer a specific relational specificity, and is by using an observational methodology when the opportunity to overcome an apparent eye to detect behavioral regularities and reduce motor occurrences to provide strategic interpretation of the teams performance.

\section{Acknowledgments}

We gratefully acknowledge the support of two Spanish government projects (Ministerio de Economía y Competitividad): 1) La actividad física y el deporte como potenciadores del estilo de vida saludable: Evaluación del comportamiento deportivo desde metodologías no intrusivas [Grant number DEP2015-66069-P, MINECO/FEDER, UE]; 2) Avances metodológicos y tecnológicos en el estudio observacional del comportamiento deportivo [PSI2015-71947-REDP, MINECO/FEDER, UE]. 


\section{References}

1. American Psychological Association (2002). Ethical principles of psychologists and code of conduct. American Psychologist, 57(12), 10601073 .

2. Anguera, M.T., Arnau, J., Ato, M., Martínez, R., Pascual, J., \& Vallejo, G. (1995). Métodos de investigación en psicología. Madrid: Síntesis.

3. Anguera, M. T., Magnusson, M. S., \& Jonsson, G. K. (2007). Instrumentos no estándar. Avances en medición, 5(1), 63-82.

4. Anguera, M. T., Blanco-Villaseñor, A., Hernández-Mendo, A., \& Losada, J.L. (2011). Diseńos observacionales: ajuste y aplicación en psicología del deporte. Cuadernos de Psicología del Deporte, 11(2), 63-76.

5. Anguera., M. T., \& Hernández-Mendo, A. (2014). Metodología observacional y psicología del deporte: Estado de la cuestión. Revista de Psicología del Deporte, 23(1), 103-109.

6. Anguera, M. T., \& Hernández-Mendo, A. (2016). Avances en estudios observacionales de Ciencias del Deporte desde los mixed methods. Cuadernos de Psicología del Deporte, 16(1), 17-30.

7. Araújo, D., Silva, P., \& Ramos, J. P. (2014). Affordance-based decisions guide team synergies during match performance. Research in Physical Education Sport and Health, 3(1), 19-26.

8. Bazanov, B., Vôhandu, P., \& Haljand, R. (2006). Factors influencing the teamwork intensity in basketball. International Journal of Performance Analysis in Sport, 6(2), 88-96.

9. Courel, J., Suárez, E., Ortega, E., Piñar, M., \& Cárdenas, D. (2013). Is the inside pass a performance indicator? Observational analysis of elite basketball teams. Revista de Psicologia del Deporte, 22(1), 191-194.

10. Cronbach, L. J., Gleser, G. C., Nanda, H., \& Rajaratnam, N. (1972). The dependability of behavioral measurements: theory of generalizability for scores and profiles. Nueva York: John Wiley and Sons.

11. Erčulj, F., \& Štrumbelj, E. (2015). Basketball Shot Types and Shot Success in Different Levels of Competitive Basketball. PloS one, 10(6), e0128885.

12. Fernández, J., Camerino, O., Anguera, M. T., \& Jonsson, G. K. (2009). Identifying and analyzing the construction and effectiveness of offensive plays in basketball by using systematic observation. Behavior Research Methods, 41(3), 719-730.

13. Gabín, B., Camerino, O., Anguera, M.T., \& Castañer, M. (2012). Lince: Multiplatform sport analysis software. Procedia-Social and Behavioral Sciences, 46, 4692-4694.

14. Garzón, B., Lapresa, D., Anguera, M.T, \& Arana, J. (2011). Análisis observacional del lanzamiento de tiro libre en jugadores de baloncesto base. Psicothema, 23(4), 851-857.

15. Ibáñez, S.J., Feu, S., \& Dorado, G. (2003). Análisis de las diferencias en el juego en función del género y categoría de los jugadores. Comunicación presentada en el II Congreso Ibérico de Baloncesto.
16. Lapresa, D., Álvarez, L., Arana, J., Garzón, B., \& Caballero, V. (2013). Observational analysis of the offensive sequences that ended in a shot by the winning team of the 2010 UEFA Futsal Championship. Journal of Sport Sciences, 31(15), 1731-1739.

17. Lapresa, D., Camerino, O., Cabedo, J., Anguera, M. T., Jonsson, G. K., \& Arana, J. (2015). Degradación de T-patterns en estudios observacionales: Un estudio sobre la eficacia en el ataque de fútbol sala. Cuadernos de Psicología del Deporte, 15(1), 71-82.

18. Magnusson, M.S. (1996). Hidden real-time patterns in intra- and interindividual behavior. European Journal of Psychological Assessment, 12, 112-123.

19. Magnusson, M.S. (2000). Discovering hidden time patterns in behavior: T-patterns and their detection. Behavior Research Methods, Instruments and Computers, 32(1), 93-110.

20. Magnusson, M.S. (2005). Understanding social interaction: Discovering hidden structure with model and algorithms. In L. Anolli, S. Duncan, M. Magnusson \& G. Riva (Eds.), The hidden structure of social interaction. From Genomics to Culture Patterns (pp. 4-24). Amsterdam: IOS Press.

21. Magnusson, M.S. (2006). Structure and Communication in Interaction. In G. Riva, M.T. Anguera, B.K. Wiederhold \& F. Mantovani (Eds.), From Communication to Presence: Cognition, Emotions and Culture Towards the Ultimate Communicative Experience (pp. 127-146). Amsterdam: IOS Press.

22. Mahlo, F. (1969). La acción táctica en el juego. La Habana: pueblo y educación.

23. Morin, E. (1990). Introducción al pensamiento complejo. Madrid: Gedisa.

24. Nunes, H., Iglesias, X., Daza, G., Irurtia, A., Caparrós, T., \& Anguera, M. T. (2016). Influencia del pick and roll en el juego de ataque en baloncesto de alto nivel. Cuadernos de Psicología del Deporte, 16(1), 129-142.

25. Ortega, E., Cárdenas, D., Sainz de Baranda, P., \& Palao, J. M. (2006). Differences between winning and losing teams in youth basketball games. International Journal of Applied Sport Sciences, 18(2), 1-11.

26. Parlebas, P. (2001). Juegos, deportes y sociedades: Léxico de praxiología motriz. Barcelona: Paidotribo.

27. Pic, M., \& Navarro, V. (In press). Triad Communication and Specificity of Motor Games. Revista Internacional de Medicina y Ciencias de la Actividad Física y el Deporte.

28. Yaari, G., \& Eisenmann, S. (2011). The hot (invisible?) hand: Can time sequence patterns of success/failure in sports be modeled as repeated random independent trials? PloS one, 6(10), e24532.

29. Zurloni, V., Cavalera, C., Diana, B., Elia, M., \& Jonsson, G. K. (2014). Detecting regularities in soccer dynamics: A T-pattern approach. Revista de Psicología del Deporte, 23(1), 157-164. 